\title{
Reconstruction of Atlantic historical winter coastal storms in the Spanish coasts of the Gulf of Cadiz, 1929-2005
}

\author{
P. Ribera ${ }^{1}$, D. Gallego ${ }^{1}$, C. Pena-Ortiz ${ }^{1}$, L. Del Rio ${ }^{2}$, T. A. Plomaritis ${ }^{2}$, and J. Benavente ${ }^{2}$ \\ ${ }^{1}$ Dept. Physical, Chemical and Natural Systems, University Pablo de Olavide. Ctra. Utrera, Km 1, 41013 Sevilla, Spain \\ ${ }^{2}$ Dept. Earth Sciences, CASEM, University of Cadiz. Av. República Saharaui s/n, 11510 Puerto Real, Cádiz, Spain
}

Received: 13 September 2010 - Revised: 28 February 2011 - Accepted: 9 March 2011 - Published: 17 June 2011

\begin{abstract}
This paper presents the reconstruction of a climatological series of winter coastal storms on the northern coasts of the Gulf of Cadiz. This series has been put together using information extracted from regional and local Spanish newspapers. It includes all the storms coming from the Atlantic sector that have been detected during the winter season, from October to March, between 1929 and 2005. In order to validate this historical storm series, it has been compared with storms series identified from quasi-observational data and using different wave heights as thresholds to decide what is to be considered as a coastal storm. Nearly 2.6 reports per year about coastal storms are published in the press which correspond to waves of $3.6 \mathrm{~m}$ high or more and to prevailing winds from a direction ranging between SSW and WNW. A long- term positive trend has been detected for the complete storm series. If only the instrumental period is analysed, no significant trend is detected. It is suggested that this difference might be associated with the impact of the North Atlantic Oscillation over the occurrence of storms in this area.
\end{abstract}

\section{Introduction}

It is widely accepted that documentary sources can provide high quality information on the past climate (Bradley and Jones, 1992; Brazdil et al., 2005; Chenoweth, 2006). Newspapers can be an excellent source of early hi-resolution instrumental data, due to their periodic nature (Gallego et al., 2007). In addition, they usually give special treatment to extreme events with a big economic or societal impact (Prieto et al., 1999; Andrade et al., 2008). In consequence, the occurrence of storms in coastal areas, as is the case of Cadiz

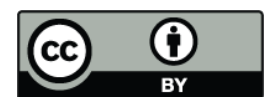

Correspondence to: P. Ribera (pribrod@upo.es) and Huelva, is a good candidate to be studied by a systematic analysis of information published in newspapers.

The Gulf of Cadiz is located between the southern coasts of the Iberian Peninsula and the northern coasts of Morocco, facing the Atlantic Ocean. The Spanish part of the Gulf extends from Gibraltar Strait to the Portuguese limit. In Spain, it includes coasts of two different administrative regions: Huelva province, to the west, and Cadiz province, to the east. Huelva coast shows, mainly, a W-E orientation; while Cadiz coast shows a general NNW-SSE orientation. Sea and swell waves generally approach the coast of the Gulf from the W and SW. Thus, a prevailing longshore current towards the $\mathrm{E}$ and SE is observed. Finally, long-term mean wave height is less than $1 \mathrm{~m}$ and, throughout this area, waves over $1.5 \mathrm{~m}$ are considered as storm waves by the Spanish Ministry of Public Works (Benavente et al., 2000).

On the Spanish coasts of the Gulf, meteorological conditions affecting fishing activities are usually registered in the local press. The press includes information about the impossibility for the fishing fleet to go out due to extremely adverse meteorological conditions (wind storms, very intense rain, wave heights...), or it reports about the loss of human lives caused by the sinking of fishing boats. For example, the ABC newspaper (2 March 1963) reported: "Cadiz Fishing Fleet remains at home: wind and rain storms have strengthened and have become more violent than in previous days..."; or El Correo de Andalucia (23 February 1966) published: "Due to the bad weather, about 24 miles away from Huelva, a hole opened in the hull of the fishing boat Masso 23. The sailors, who were not able to repair it, were helped by the fishing boat Badaya, which took the 17 sailors safely back to Huelva. The current carried the Masso 23 and smashed it against the reef".

Maritime transport is also affected by storms. For example when the ferry connecting Spain and North Africa through the Gibraltar Strait was interrupted, the press informed about it. A good example of how these cases appear in the press can

Published by Copernicus Publications on behalf of the European Geosciences Union. 
be found in El Correo de Andalucia (12 December 1980): "Since the day before yesterday at 06:00 p.m. and due to the strong winds from the East, the passenger connection between Algeciras, Ceuta and Tanger has been stopped. The intense Levante (local name for the wind blowing from the East, often characterised by high speeds) has led the Algeciras Port Authority to cancel all passenger departures from Algeciras Harbour. The intensity of the gale can be noticed in the northern dike of the city harbour, which is over-passed by the waves creating a strange and beautiful spectacle...".

In some cases, the destruction of coastal infrastructure is described in the press: Diario de Cadiz (22 December 1945): "Yesterday morning, due to the violence of the waves over the Southern Walls, a hole 80 centimetres in diameter was produced in the maritime sidewalk ..."; or Diario de Cadiz (27 October 1967): "A very intense wind and rain storm has produced such high waves in the harbour of Cadiz that much damage has been caused. Some waves reached a height of 20 meters and caused great damage in the breakwater and the jetty of the city...".

Descriptions of morphological impacts of coastal storms on beaches are often found in the local press: Diario de Cadiz (28 December 1995): "Rota: the storm has caused big damage to the town coastline. ... in La Ballena beach, some meters of sand have been swept away by the waves while almost all the sand is gone from Punta Candor beach. The Coastal Authority has indicated that, in the old times, when storms similar to these occurred, the sand practically disappeared from the beaches but, usually, it came back to the beaches the following Spring...".

These examples show the potential of newspapers to construct series of extreme events in the Gulf of Cadiz related to destructive coastal events. The aim of this work has been to build a comprehensive historical series of coastal storms on the Spanish coasts of the Gulf of Cadiz by using information from historical data extracted from newspapers published in this region. The new series will be then compared to instrumental data currently used to study the series of storms in the area.

\section{The newspapers in the Gulf of Cadiz}

In order to build a series of historical storms in the Gulf of Cadiz, a review of local, regional and national newspapers has been performed. Useful data for the period 1929-2005 were found. The selection of the newspapers to be reviewed was done according to the following criteria:

- Series of regional newspapers had to be available covering the whole period. In consequence, the number of available newspapers to be reviewed is highly reduced due to the length of the analyzed period. Only regional or national newspapers have been published covering the whole area and throughout the complete analysis period.

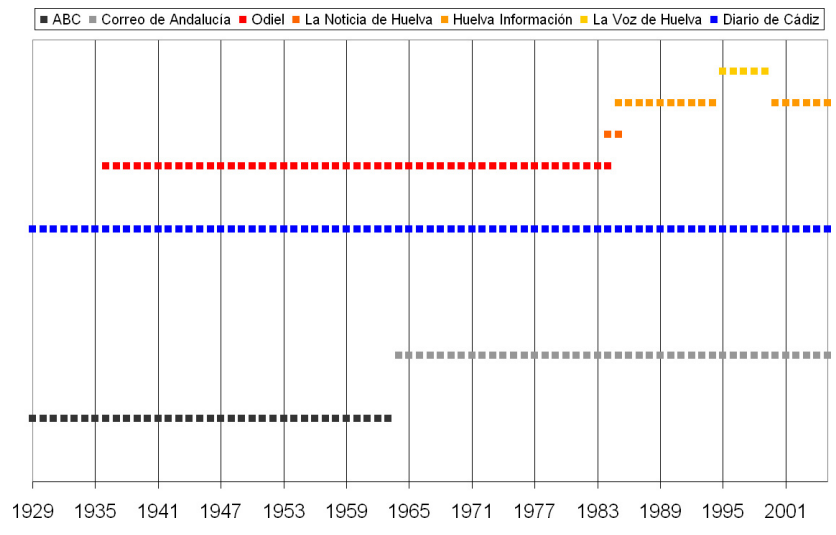

Fig. 1. Newspapers used in the review and the period they covered. Regional press is represented in gray scale and local press in colour scale.

- The newspapers must contain information about local impacts, so we preferred regional and local press published along the Atlantic coasts of Andalusia (Huelva and Cadiz provinces).

In this way, the search for information about storms was initially based on the regional press where references to meteorological phenomena in Huelva or Cadiz were identified. In this first stage, no single paper was found which covered the whole period, thus, a comprehensive review on a daily scale was done with the newspapers "ABC" and "El Correo de Andalucia". A chronology of intense meteorological events was developed. The addition of these two papers covered the whole 1929-2005 period.

The next step was to review the available local press to look for the local impacts of each storm found in the general chronology. Five local newspapers were needed to completely cover the period 1929-2005. Local press was thus used to obtain a precise description of each particular event found at regional scale, the associated phenomena, its location and its impact. Figure 1 summarises the newspapers used in the search for historical storms and information about the period covered by each one. It must be stressed that local press sources are substantially different for Huelva and Cadiz. While information about Cadiz was obtained from a single newspaper (Diario de Cadiz), four different newspapers (Huelva Informacion, La Noticia de Huelva, La Voz de Huelva and Odiel) were needed to complete the information about Huelva, particularly during the last $20 \mathrm{yr}$ of the study period.

A digital database was developed where all the information extracted from the press was registered. The complete database contains 751 records, with meteorological or socioeconomic information which was considered as possibly related to the occurrence of storms on the coasts of the Gulf of Cadiz. Each record contains information about the date of the event, the source of the information and the description 
of the phenomenon. After collecting all the candidates to be classified as a storm, a closer scrutiny had to be performed to discard any possible spurious event. Examples of records that were not storms are floods caused by heavy rainfall but neither on the coast nor from a single storm, but in the inland areas or caused by persistent rain. Another example are those records with general descriptions of bad weather affecting the whole region, or even the whole Iberian Peninsula, but not directly linked to a coastal storm in the Gulf area. To be definitively classified as a storm, the data collected in the newspaper must include the description of the coastal storm itself or information about morphological or socio-economic impacts associated with it.

Finally, three different categories of storms were created considering the description included in the papers: wind storm, rain storm and electrical storm. This classification is not mutually exclusive and one record can be considered as representative of more than one of these categories. In fact, electrical storms are always included in, at least, one of the other storm types. No specific classification has been created for other meteorological information but, in their descriptions, some records provide information about other phenomena such as fog or hail. This classification was performed in order to check if historical wind storms were better correlated with instrumental storms than the complete historical storm series. They were not, and in this paper, the complete series of storms, including wind and rain storms, is presented.

A secondary classification of the records was created as a function of the location of the storms. Three different areas could be discriminated: Gibraltar Strait, Cadiz and Huelva. Again, many records included information about a storm affecting more than one of these sites. This division was done in order to test if storms affecting the city of Cadiz produced a chronology better correlated with modern instrumental data than the chronology constructed from the total number of storms in the Gulf area. Again, it was found that the complete chronology correlates much better with the instrumental series than the Cadiz series alone ( $r=0.606$ vs. $r=0.456$ for the complete series and defining storms for waves higher than $3.6 \mathrm{~m}$ ). We find this result reasonable because, even when the storm impact can be more noticeable over particular areas of the Gulf, and thus, be described in the press only for those areas, storms arriving from the Atlantic usually affect the whole Gulf area.

Storms in the Gulf of Cadiz, as in most of the western side of the Iberian Peninsula, are closely related to low pressure systems coming from the Atlantic (Trigo et al., 2002, 2004; Trigo, 2006; Gallego et al., 2007). Consequently, it was mandatory to know wind direction at a daily scale in order to be able to classify storms as a function of the wind direction on the different storm days. The longest available series of wind direction representative of this area with reliable data at daily scale capable to going back to 1929 is the ICOADS database (International Comprehensive OceanAtmosphere Data Set) (Worley et al., 2005). This database consists of millions of individual marine wind observations covering the entire globe. In our analysis, we selected those records collected within the region represented by the square in Fig. 2 and computed the wind averages on a daily basis. The average direction of the wind for every day was used to classify the prevailing wind direction in the Gulf of Cadiz and, thus, to identify the direction from which storms reached the coasts of the Iberian Peninsula. In fact, the square in Fig. 2 was chosen to represent the atmospheric disturbances coming from the west related to storm occurrence in this area. Even though the ICOADS database covers the period 1850 -present, the early data may be scarce in some parts of the world. In fact, in the selected area, the number of wind records is highly reduced before 1902, but covers the 20th century correctly. In this way, this paper includes a classification of historical storms attending to the wind direction in the area.

\section{Validation of the reconstructed series}

In order to test the historical storm series, wave height data from the HIPOCAS database (HIndcast of dynamic Processes of the Ocean and Coastal Areas of Europe) was used. These data stem from high-resolution numerical modelling, cover at a daily scale the period 1958-2001 and they are considered the best available source for long-term wave data throughout the area (Guedes-Soares et al., 2002). These data provide an overlapping period of $44 \mathrm{yr}$ with the historical series. For this study, we chose the nearest grid-point to Cadiz (see Fig. 2) and selected the significant wave height $\left(H_{m 0}\right)$ as the parameter to represent the strength of the storm.

In order to construct an instrumental series of the annual number of storms in the Gulf of Cadiz based on the $H_{m 0}$ parameter of HIPOCAS, different wave-height thresholds have been tested. Only winter storms have been accounted for, considering that winter lasts from October one year to March the following year. This discrimination is due to the fact that, for this area, it is during this season when wave energy reaches its maximum value (Rodriguez-Ramirez et al., 2003). Currently, the Spanish National Port Authority proposes to use $H_{m 0}=1.5 \mathrm{~m}$ as a threshold to identify coastal storms (MOPT, 1992), thus, HIPOCAS data has been used to construct a yearly storm series in the Gulf of Cadiz using this threshold. However, the annual number of storms using this threshold was very high (more than 40 storms per year); thus an additional series for the annual number of storms have been constructed using the 90, 92, 94, 96, 98 and 99 percentiles of the wave height series.

The validation of the historical series was then done by comparing it with the different instrumental series by means of the corresponding Pearson correlation coefficients for the period 1958-2001. Correlations were calculated in a multivariate scheme for all the different wave-height thresholds and discriminating storms by using different wind direction 

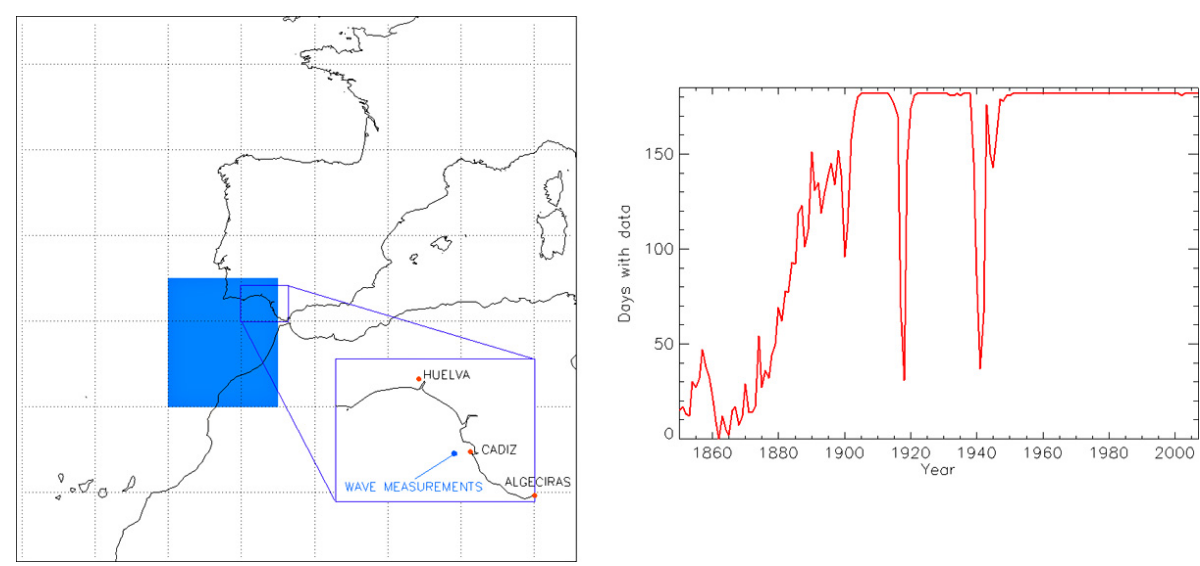

Fig. 2. Area selected to compute wind averages from the ICOADS database and some significant locations (left); number of winter (OctoberMarch) days with ICOADS wind observations inside the selected square (right).

windows. These windows were selected to be $90^{\circ}$ wide and were calculated every $5^{\circ}$ from $0^{\circ}$ to $355^{\circ}$.

\section{Results}

As stated in the previous section, the historical storms database contains 751 records. A first classification showed that, from those, 616 records (corresponding to 523 storm days) were included in, at least, one of the storm categories described. There were 383 included as wind storms, 463 as rain storms and 45 contained information about an electrical storm. Additionally, 21 records included information about fog and 26 records described the presence of hail. All hail days but one were included in, at least, one of the other storm categories and only 6 fog days were included in, at least, one of the storm categories.

The total number of coastal storms is reduced when the site analysis is done by including the description in the local press of a storm's impacts. Only records about 361 days of the 523 storm days include information about its impact on the coast. Finally, 226 records referred to storms in the vicinity of the city of Cadiz, 172 near Huelva and 194 near Gibraltar Strait.

When the seasonal separation was done, only 26 records were excluded from the total list and a final number of 335 records describe storms occurring during winter, from 1 October in one year to 31 March, the year after. That produces a mean number of 4.3 storms per year during the period 1929-2006.

When the HIPOCAS database is analysed with the recommended wave height of $1.5 \mathrm{~m}$ as the threshold to define a coastal storm, the mean annual number of winter storms rises to 44.5. This number of storms per year would mean that a coastal storm occurs one day in every four and that is clearly not the case over this area. When the $90(1.8 \mathrm{~m}), 92(2.0 \mathrm{~m})$, $94(2.2 \mathrm{~m}), 96(2.5 \mathrm{~m}), 98(3.1 \mathrm{~m})$ and $99(3.6 \mathrm{~m})$ percentiles of the winter series of $H_{m 0}$ are considered, the mean number

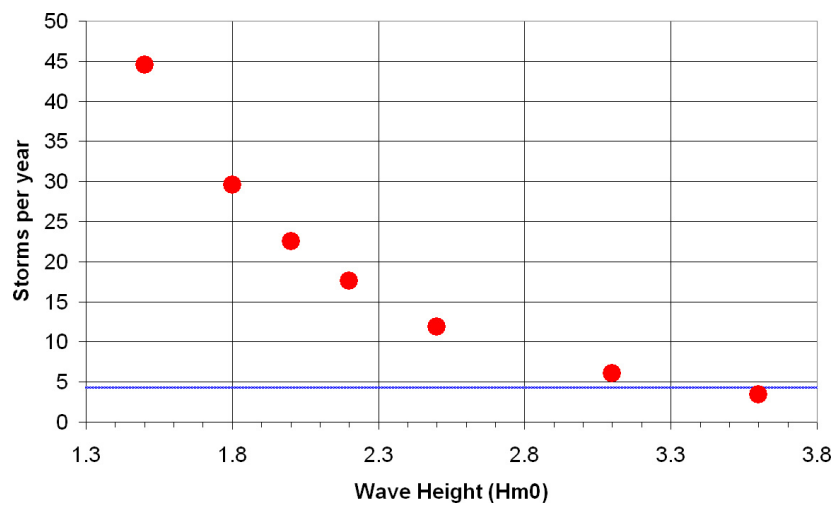

Fig. 3. Mean number of winter coastal storms obtained from HIPOCAS database using different wave height thresholds to classify what a storm is $(1.5 \mathrm{~m}$ and percentiles $90(1.8 \mathrm{~m}), 92(2.0 \mathrm{~m})$, $94(2.2 \mathrm{~m}), 96(2.5 \mathrm{~m}), 98(3.1 \mathrm{~m})$ and $99(3.6 \mathrm{~m}))$. The blue line shows the mean number of news reports about winter storms published in the press.

of coastal storms are reduced to 29.6, 22.5, 17.6, 11.9, 6.1 and 3.4 storms/winter. Attending to these figures, it is apparent that newspaper report storms defined by a $H_{m 0}$ value situated between percentiles 98 and 99 of the HIPOCAS series, corresponding to waves between $3.1 \mathrm{~m}$ and $3.6 \mathrm{~m}$ in height (Fig. 3). But again, if the direction of the wind is considered to characterize the annual number of winter storms, this situation varies slightly.

Figure 4 shows the mean number of winter storms during the period 1958-2001, both for the instrumental record (percentile 99, dashed line) and for the historical record (solid line) as a function of the direction of the wind in the area. These values have been calculated using a moving window, 90 degrees wide, centred on the direction indicated in the horizontal axis. Storm occurrences smaller than 1 storm/yr are not represented in this figure. Additional analysis using 
different window sizes were preformed (not shown), but the results obtained were quite similar to those presented here. From Fig. 4, it becomes clear that most of the storms in the area are produced when the wind blows from a direction ranging from south to northwest, with a maximum when those windows are centred at an angle situated between $240^{\circ}$ and $260^{\circ}$ (windows ranging from $195^{\circ} \mathrm{SSW}$ to $305^{\circ} \mathrm{WNW}$ ). When the historical and instrumental mean annual number of winter storms are counted using the $90^{\circ}$ windows centred at those angles, their numbers become very similar, being lowered to about 2.5 storms per year, for the historical record, and 2.9 storms per year for the instrumental one.

There are different reasons for this diminution. It is well known in the area that when the Levante blows, conditions become warm and dry. In general, Levante winds can produce unpleasant conditions but, usually, they are related neither to intense storms nor to very high waves, which could produce socioeconomic or morphological impacts on the Atlantic coast of the province. Previous studies showed that storms coming from the 3rd and 4th quadrant (Atlantic) are characterized by a longer fetch responsible for the generation of high waves, surge and, consequently, coastal damage. Thereby storms caused by easterly winds did not generate high waves or storms surge - nor big coastal damage - due to the short fetch in this direction (Rodríguez-Ramírez et al., 2003; del Río et al., 2011). In any case it is not unusual for Levante storms to produce adverse weather conditions in the Strait area and, in some cases, cause difficulties in the maritime transport between Algeciras (Spanish coast of the Gibraltar Strait) and Ceuta or Tanger (African coast of the strait). As a matter of fact, this is the most common reason for Levante wind storms to appear in the local press. These storms show up in the press about 0.75 times per year during the instrumental period. In fact, news in the press about Levante storms are partially responsible for the difference between the number of storms per year in the complete historical chronology and its value when only southwesterly to westerly winds are considered.

The correlation between the historical and the instrumental storm chronologies between 1958 and 2001 is shown, as well, in Fig. 4. The correlations have been computed using 90 degrees moving windows of wind direction and different wave heights, from 1.5 to $3.6 \mathrm{~m}$, as thresholds to define coastal storms. Correlations are generally very low for wave heights below $2 \mathrm{~m}$ and for wind directions different to those included in the range 170 to 270 degrees. The relatively good correlation for low wave heights with winds from 145 degrees is not very representative of the climatology of the region, due to the extremely low number of storms per year when wind blows from those directions. In fact, a detailed analysis of the correlations obtained shows that the best agreement between the historical and the instrumental chronologies is obtained for the 195-285 degrees window, with significant correlations with values around $r=0.68$ ( $p<0.01$ ) for wave heights of $2.5 \mathrm{~m}$ and higher.

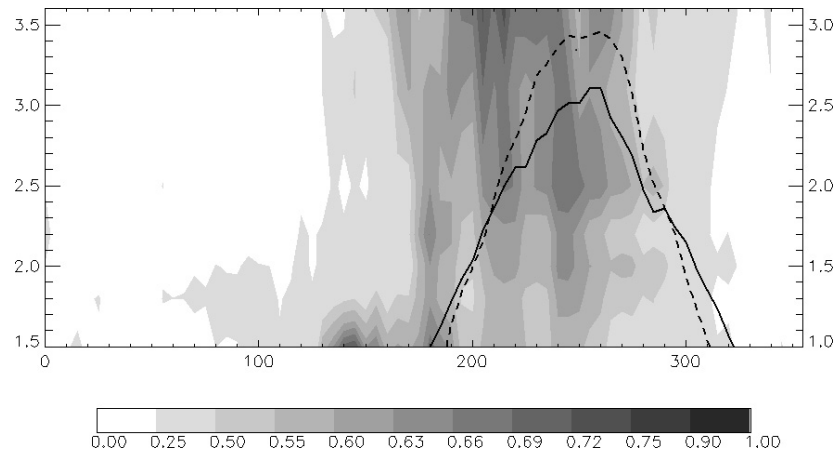

Fig. 4. Gray scale indicates the value of Pearson correlation coefficients between historical storm series and instrumental storm series constructed using different wave height thresholds (left vertical axis), for 1958-2001 with a $90^{\circ}$ wide window centred in the direction indicated in the horizontal axis. The mean number of winter storms, depending on wind direction, is included in the right vertical axis and is shown by the solid line (number of historical storms) and the dashed line (number of storms with waves $3.6 \mathrm{~m}$ high (percentile 99) or higher).

Figure 5 includes both the historical and the instrumental storm series (using the percentile $99-3.6 \mathrm{~m}$ of the wave height series as a threshold) for the 195-285 degrees window. Both series are characterized by very high variability, with values ranging from 0 storms in some years to as much as 10 storms in a single year. This variability seems to be higher in the second half of the analyzed period. The comparison between the instrumental and the historical series shows that, despite the close agreement between both series $(r=0.682)$, it is evident that the historical series slightly underestimates the annual number of storms, particularly in those years with higher storm occurrence.

Figure 5 includes, as well, the representation of linear trends for both series. It shows that none of them has a significant trend during the instrumental period, but that a small, positive and significant $(p<0.05)$ trend of 0.21 storms/decade is detected when the complete historical period is analyzed. This trend implies that the number of news about storms published in 2005 is about 55\% higher than in 1930.

Spectral analysis of the complete and instrumental series has been performed. No significant band of oscillation was found for the complete series but a near $6 \mathrm{yr}$ significant oscillation band was found for the instrumental period (Fig. 6). This period is similar to that found by Rodriguez-Ramirez et al. (2003), when analysing winter storms on the coasts of Huelva during $40 \mathrm{yr}$ through the second half of the 20th century. They found, as well, a quasi-decadal oscillation band not identified in the series presented in this paper.

As stated in previous paragraphs, storms in the Gulf of Cadiz are closely related to low pressure systems coming from the Atlantic. The North Atlantic Oscillation (NAO) is the main climatic pattern over the area and influences the 

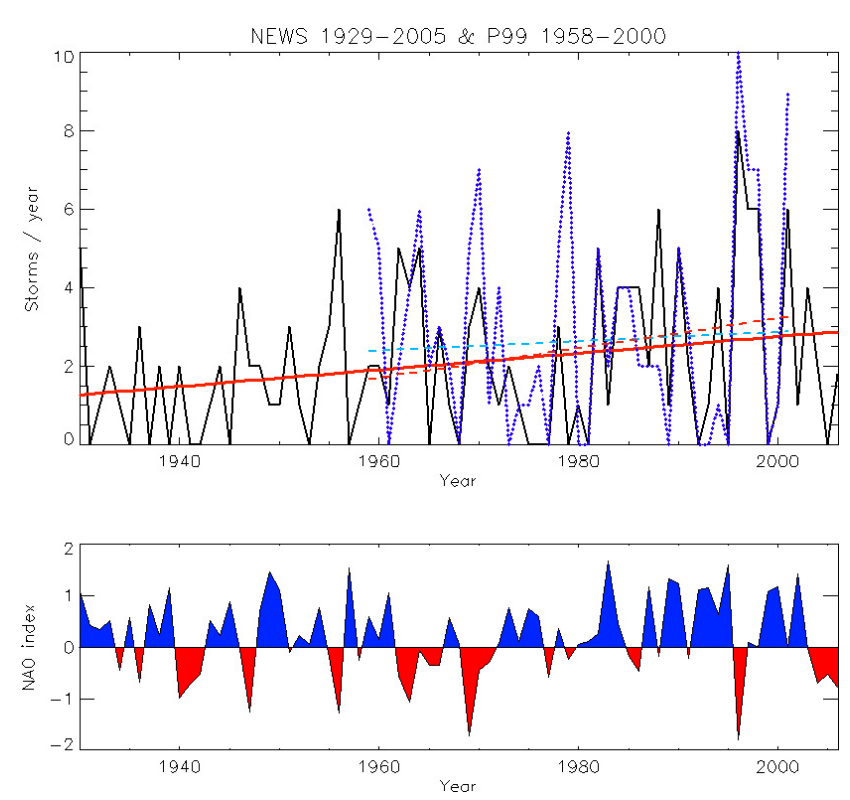

Fig. 5. Series of storms from newspaper records (black solid line), percentile 99 of instrumental records (blue dotted line) when wind comes from 195-285 degrees. Trend lines for news series in red for the whole period and for the instrumental period and in blue for the instrumental series (solid line means significant $-p<0.05-$ and dashed line means not significant). Evolution of the winter NAO index in the lower panel.

storm track position, particularly during winter (Trigo et al., 2002, 2004; Trigo, 2006). In fact, Gallego et al. (2005) found that winter NAO affected both the frequency and the accumulated precipitation of intense rainfall events over the Southwest of the Iberian Peninsula. As well, Andrade et al. (2008) identified a negative correlation between NAO and Azores storm series obtained from newspapers. A detailed analysis of Fig. 5 shows the existence of a negative correlation between the annual number of winter storms and winter NAO index (mean value of the Climatic Research Unit NAO index from October one year to March the following year http://www.cru.uea.ac.uk/cru/data/nao/). In this paper, and in order to analyse if NAO had a noticeable impact on storm occurrence over the area, percentiles 10 and 90 of the winter NAO index series for the complete and for the instrumental periods were identified. Then, the mean number of winter storms was calculated for those years. In all cases, the number of winter storms was higher during the negative phase of NAO. For the historical chronology, there are 3.38 storms per year during negative NAO years and 1.38 during positive NAO years. During the instrumental years the situation is very similar. Positive phase years have a mean value of 1.80 storms per year both in the historical and the instrumental data (storms defined by waves higher than $3.6 \mathrm{~m}$ ), while the negative phase mean values are 4.00 for the historical data and 4.2 for the instrumental data. It must be stressed that the low number of cases implies that these differences become

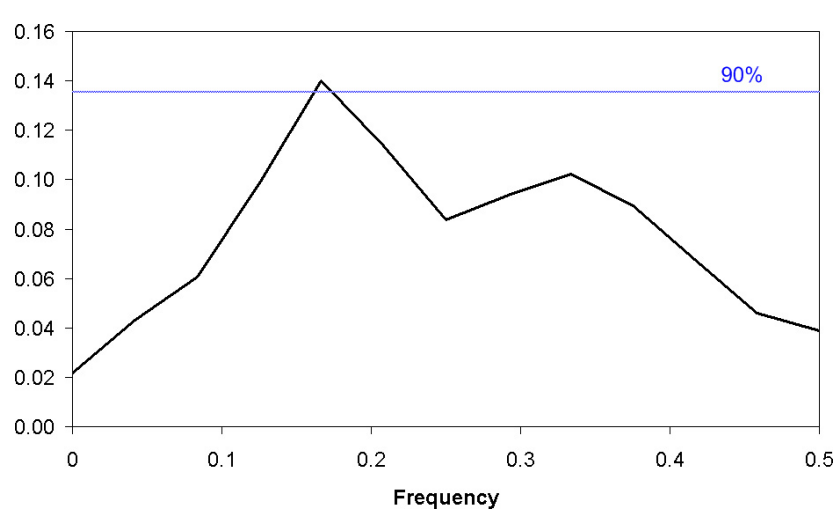

Fig. 6. Spectral analysis of the winter storms series obtained using $3.6 \mathrm{~m}$ as wave height threshold to define a storm.

statistically significant only for $p<0.2$. If percentiles 20 and 80 are used, the characteristics are very similar but the difference between mean numbers in the different phases is, usually, slightly reduced.

Even if speculative, these differences in the number of storms associated with the NAO could, somehow, be affecting the differences between trends in the two analyzed periods. When those trends are calculated for the NAO index, no trend is detected for the whole period, while a positive and significant trend is characteristic for the NAO series during the storm series instrumental period. Thus, if the long term trend in the number of winter storms is caused by an external factor different to NAO, the impact of that factor could be mitigated due to the opposite effect exerted by NAO during the second half of the 20th century.

\section{Discussion and conclusions}

A new $76 \mathrm{yr}$ long series of coastal storms on the Spanish coasts of the Gulf of Cadiz has been developed from information appearing in local and regional newspapers. This series has been checked against instrumental series during the second half of the 20th century and a close agreement between both series has been found.

The correlation between the historical storm series and the instrumental one reaches a high degree of agreement for wave heights higher than between 2.2 and $2.5 \mathrm{~m}$. Thus, those heights could be good candidates as thresholds to define coastal storms in the area instead of the current recommended value of $1.5 \mathrm{~m}$. However, the best correlation between the instrumental and the reconstructed series is obtained when the storms are defined using a wave height threshold of $3.6 \mathrm{~m}$. In addition, for this threshold, the annual number of storms is quite similar for both historical and instrumental series so, probably, $3.6 \mathrm{~m}$ could be used as an optimum threshold to identify storms with a sensible impact on the Spanish coasts of the Gulf of Cadiz. In a recent paper by Del Rio et al. (2011), where the morphological impact 
of coastal winter storms in the coasts of Cadiz are studied, it was suggested that $3.3 \mathrm{~m}$ was the wave height needed to produce a morphological impact on those coast. Our result, found independently, seems to confirm this value.

It has been seen that the impact of the coastal storms, both in the historical and in the instrumental series, is most intense during the cold half of the year - October to March - and that the wind direction plays an essential role in the coastal impacts of a storm. Storms have a more noticeable impact on the coast when their wind direction ranges from SSW to the WNW. As a matter of fact, very similar results were obtained by Rodriguez-Ramirez et al. (2003) when they analyzed the storms affecting the coast of Huelva during the period 1956-1996. Those wind directions, very much perpendicular to the Spanish shoreline of the Gulf of Cadiz, favour the surge formation. Additionally, storms from those directions are the ones with the highest fetch over this area (Del Rio et al., 2011). Other wind directions are not so perpendicular to these coasts and, consequently, the impact of the storms is reduced. Finally, the northern coast of the Gulf of Cadiz is partially protected against storms from wind directions different to the third quadrant due to its geographical configuration (see Fig. 2).

When the relatively short instrumental series for the wave height is considered, no significant trend for the annual number of storms is found. However, when the historical data, which extends back to 1929 , is analysed, a significant increase of 0.21 storms per decade in the annual number of storms is found. It has been proposed that these differences could be associated with the evolution of the NAO during those same periods, since it has been observed that there is a tendency for more storms to occur over this area during those years when NAO is on its negative phase and it is well documented that NAO was characterized by a positive trend during the second half of the 20th century (Hurrell, 1995). Thus, the evolution of the NAO could be affecting the number of intense coastal storms impacting throughout the area.

Newspapers have proven to be a useful source with which to construct storm chronologies for the coasts of the Gulf of Cadiz. The chronology presented in this paper seems to slightly underestimate the annual number of winter storms, being the mean number of winter storms identified from instrumental data about $15 \%$ higher than those identified from news in the press. Our hypothesis is that there are different reasons for this. On one hand, newspapers tend to publish only what is new and, consequently, if many consecutive storms occur in a brief period of time, most probably there will be only one or two articles accounting for those storms, describing one of them or the fact that there have been many consecutive days with bad weather conditions, while in the instrumental record, all the days with waves higher than the selected threshold will be accounted for as storms. On the other hand, we have produced a storm classification according to the associated wave height. This height is directly linked to the storm intensity, but the damage produced by those waves can be very different depending, among other factors, on the phase of the tides. Since newspapers will only publish, or at least most frequently will only publish, news about storms with noticeable impacts, two similar storms, one occurring during neap tides and the other during spring tides, will have different impacts on the coasts and will be very differently treated in the press. It is very likely that, unless they are very intense storms, only the ones during spring tides will be referenced in the local press.

Acknowledgements. This work is a contribution to the project MICORE (EU grant FP7-ENV-2007-1-202798) and to the research groups RNM-356 and RNM-328 of the PAI. The authors would like to acknowledge Puertos del Estado for providing wave data.

Edited by: J. A. Jimenez

Reviewed by: two anonymous referees

\section{References}

Andrade, C., Freitas, M. C., Trigo, R. M., Gallego, M. C., Borges, P., and Ramos, A. M.: Comparing historic records of storm frequency and the North Atlantic Oscillation (NAO) chronology for the Azores region, Holocene, 18, p. 754, doi:10.1177/0959683608091794, 2008.

Benavente, J., Gracia, F. J., and López-Aguayo, F.: Empirical model of morphodynamic beachface behaviour for low-energy mesotidal environments, Mar. Geol., 167, 375-390, 2000.

Bradley, R. S. and Jones, P. D. (Eds): Climate Since AD 1500, Routledge, London, 679 pp., 1992.

Brazdil, R., Pfister, C., Wanner, H., von Storch, H., and Luterbacher, J.: Historical climatology in Europe - The state of the art, Climatic Change, 70, 363-430, 2005.

Chenoweth, M.: A reassesment of historical Atlantic basin tropical cyclone activity, 1700-1855, Climatic Change, 76, 169-240, doi:10.1007/s10584-005-9005-2, 2006.

Del Rio, L., Plomaritis, T. A., Benavente, J., Valladares, M., and Ribera, P.: Establishing storm thresholds for the Spanish Gulf of Cadiz coast, Geomorphology, in press, 2011.

Gallego, D., García-Herrera, R., Calvo, N., and Ribera, P.: A new meteorological record for Cadiz (Spain) 1806-1852, Implications for climatic reconstructions, J. Geophys. Res., 112, D12108, doi:10.1029/2007JD008517, 2007.

Gallego, M. C., Garcia, J. A., and Vaquero, J. M.: The NAO signal in daily rainfall series over the Iberian Peninsula, Climate Research, 29(2), 103-109, 2005.

Guedes-Soares, C., Weisse, R., Alvarez, E., and Carretero, J. C.: A 40 Years Hindcast in European Waters, Proceedings of the 21st International Conference on Offshore Mechanics and Arctic Engineering (OMAE 2002), ASME (2002) Paper OMAE20022860.

Hurrell, J. W.: Decadal trends in the North Atlantic Oscillation: regional temperature and precipitation, Science, New Series, 269(5254), 676-679, 1995.

MOPT: Recomendaciones para trabajos marinos (ROM) 0.3-91 Oleaje, Anexo I: Clima marítimo en el litoral español, Ministry of Public Works and Transport, Madrid, 1992. 
Prieto, R., Gimeno, L., García, R., Herrera, R., Hernández, E., and Ribera, P.: Interannual variability of hail-days in the Andes region, Earth Planet. Sci. Lett., 171, 503-509, 1999.

Rodriguez-Ramirez, A., Ruiz, F., Caceres, L. M., Rodriguez-Vidal, J., Pino, R., and Muñoz, J. M.: Analysis of the recent storm record in the southwestern Spanish coast: implications for littoral management, Sci. Total Environ., 303, 189-201, 2003.

Trigo, I. F.: Climatology and interannual variability of stormtracks in the Euro-Atlantic sector: a comparison between ERA40 and NCEP/NCAR reanalyses, Clim. Dynam., 26, 127-143, doi:10.1007/s00382-005-0065-9, 2006.
Trigo, R. M., Osborn, T. J., and Corte-Real, J. M.: The North Atlantic Oscillation influence on Europe: climate impacts and associated physical mechanisms, Clim. Res., 20, 9-17, 2002.

Trigo, R. M., Pozo-Vazquez, D., Osborn, T. J., Castro-Diez, Y., Gamiz-Fortis, S., and Esteban-Parra, M. J.: North Atlantic Oscillation influence on precipitation, river flow and water resources in the Iberian Peninsula, Int. J. Climatol., 24, 925-944, 2004.

Worley, S. J., Woodruff, S. D., Reynolds, R. W., Lubker, S. J., and Lott, N.: ICOADS Release 2.1 data and products, Int. J. Climatol., 25, 823-842, 2005. 